\title{
Marital Adjustment among Women: A Comparative Study of Nuclear and Joint Families
}

\author{
Kanchan Sabre ${ }^{1 *}$
}

Marital adjustment denotes emotional stability, intellectual efficiency and social effectiveness people. He present study is an attempt to ascertain the level of marital adjustment among women with reference to their type of family belonging to Madhya Pradesh. For the conduction of study a sample of 120 women (nuclear family=60 \& joint family=60) was purposively selected. The measure used for data collection was Pramod, K.; Kanchana, R. Marital Adjustment Scale. The data was analyzed by computing Means, SD, \& t-test. The results revealed that there was a significant difference in marital adjustment among women of nuclear and joint families. The women belonging to nuclear showed higher levels of marital adjustment as compared to women of joint families.

Keywords: Marriage, Marital Adjustment, Family.

Marriage is a very divine and pure thread which binds two souls together. Individual is a universe and marriage merge two universe and permits them to move parallel.

One definition of adjustment is adaptation behavior that permits us to meet the demand of the environment (Kalpana, D. B.; Pravin, A. B., 2013). Marriage is by far the most important personal relationship for any person and has been described as the most intimate, delicate and far reaching relationship between man and woman. The stability and continuity of a marriage is important not just to the members of the marital dyad, but to their family and community as a whole. Traditionally, in Indian culture, people expected their marriages to be arranged by their elder extended kin who continued to play a significant role in the couple's lives. Marriage has been discussed in terms of the interdependence between two individuals (Lewin, 1948) and what happens to one individual is likely to influence the other. As a function of the interdependence in relationship, the nature of the relationship may undergo transformation to accommodate the changes in the partner's health and behavioural status (Kerns \& Turk, 1985). Marriage is for pleasure, happiness and peace of mind on account of satisfaction through interactions with

\footnotetext{
${ }^{1}$ Research Scholar, Department of Psychology, Barkatullah University, Bhopal, M. P., India

*Responding Author

(c) 2016 I K Sabre; licensee IJIP. This is an Open Access Research distributed under the terms of the Creative Commons Attribution License (http://creativecommons.org/licenses/by/2.0), which permits unrestricted use, distribution, and reproduction in any Medium, provided the original work is properly cited.
} 
others, trust, understanding and fulfilling social obligations and enriching personality development (Goel et al., 2013).

Marital adjustment denotes emotional stability, intellectual efficiency and social effectiveness people. Marriage is the key to whole some adjustment involvement and satisfaction. Marital adjustment seems complex than it may appear. Basically, in marriage, two persons adjust to each other's sensory, motor, emotional and intellectual capacities. On the personality level they must adjust together to their total environment, including such matters as a new household, children,

provision and preparation of food, relatives, friends, relations and work (Fonseca, 1966). The success of marital life much depends upon the success in marital adjustment by the husband and wife. Marital maladjustment results in conflicts and tensions and many a time divorce.

Marital adjustment is a process which is created during couples' life because it is necessary for taste conformity, person's traits recognition, behavioral rules creation and relational models formation. Thus, marital adjustment is an evolutional process between a couple (Aminjafari, 2012). Marital adjustment has been related to personality, job \& home stresses, mental illness, depression, education, sex role attitude, happiness and success in life (Hashmi et al, 2007).

\section{Marital Problems}

A background of patterns of marital interactions, roles, and power in India is essential before we review research on marital problems. However, studies on family in India have generally concentrated on the joint family, with a patriarchal structure. It has been largely recognized that conjugal relations have little significance in the joint family (Ramu, 1988). Consequently, marital interaction, role, and power have received scant attention. The few studies that are identified in this area are grouped and described below.

\section{Marital Adjustment versus Maladjustment}

Marital adjustment refers to a state of accommodation which is achieved in different areas where conflict may exist. Srivastav, Singh, and Nigam (1988) studied the effect of certain demographic characteristics such as age differences, duration of marriage, education, occupation, socioeconomic status, and number of children on marital adjustment. The analysis indicated that age difference between husband and wife highly contributed towards marital adjustment. Secondly, differences in educational level of the spouses were more evident in the maladjusted couples. Shukla (1988) observed that as compared to the single career couples, more of the dual career couples expected that the husband and the wife should be about equally responsible for the provider and the housekeeper roles, and evaluated the wives more favorably in the provider role and the husbands in the housekeeper roles. It is interesting, though, that in both the groups, wives derived greater happiness in their marriages when they were satisfied with the housekeeper role and evaluated their husbands favorably in the provider role. 


\section{Family}

The term family is derived from the Latin word 'familia' denoting a household establishment and refers to a "group of individuals living together during important phases of their lifetime and bound to each other by biological and/or social and psychological relationship" (Sethi, 1989). The group also includes persons engaged in an ongoing socially sanctioned apparently sexual relationship, sufficiently precise and enduring to provide for the procreation and upbringing of children (Sethi, 1989). Unlike the western society, which puts impetus on "individualism", the Indian society is "collectivistic" in that it promotes interdependence and co-operation, with the family forming the focal point of this social structure. The Indian and Asian families are therefore, far more involved in caring of its members, and also suffer greater illness burden than their western counterparts. Indian families are more intimate with the patient, and are capable of taking greater therapeutic participation than in the West.

Family may be broadly defined as a unit of two or more persons united by marriage, blood, adoption, or consensual union, in general consulting a single household, interacting and communicating with each other (Desai, 1994).

There was virtually no scope to exit without being a member of a family. According to Census of India (Ministry of Home Affairs, 1991), Indian families comprise largely of nuclear family structure with joint families forming about a fifth of the total households (Census of India, 1981).

\section{OBJECTIVES}

1) To study marital adjustment of women with reference to their type of family (nuclear and joint families).

2) To study significance of difference of marital adjustment among women with reference to their type of family (nuclear and joint families).

\section{Hypothesis:}

$H_{O} 1$ : There is no significant difference in marital adjustment among women with reference to their type of family (nuclear and joint families).

\section{METHODOLOGY}

\section{Design:}

The independent variable in this study, i.e., type of family categorized in two levels (nuclear \& joint families) and dependent variable i.e., level of marital adjustment. The sample was compared with reference to demographic variable 'type of family' (nuclear \& joint families). The data collected from the sample was analyzed by various statistical techniques such as Mean, SD, and t-test with the help of SPSS. 


\section{Sample:}

The research consists of 120 married women of M.P. (nuclear families=24 \& joint families=24), who were selected by purposive sampling.

Inclusive criteria: The selected are married women and permanent residents of Madhya Pradesh. They fall in the age group between 22 to 40 years and all are non-working women.

Exclusive criteria: Unmarried women who do not belong to Madhya Pradesh and does not fall in the age range of 22-40 years. Working women are also excluded.

\section{Calculation:}

A standardized questionnaire was distributed to a purposively selected sample of 120 married women of M.P. The questionnaire consisted of structured questions with dichotomous options. For achieving the desired objectives, the collected data was analysed by using the following statistical techniques:

Descriptive statistics such as Mean, SD etc. was used in order to make raw data tangible. t-test was used to assess the significance of means difference between different variables.

\section{Tool Description:}

The following standard tool was administered to gather the information from the participants for the present study:

\section{Marital Adjustment Scale}

The Pramod Kumar and Kanchana Rohatdi's Marital Adjustment scale is a simple measure of marital adjustment. The measure can be used as a brief screen to identify degree of marital adjustment. The scale involves 25 questions with dichotomous options (Yes / No). A 'yes' response is assigned a score 1 except for items 4, 10 and 19 in which case reverse is applicable. The sum of these values gives the marital adjustment score for the husband or the wife. Since the responses contributing towards marital adjustment are given a score, the higher the total score, the higher would be the marital adjustment of the husband or wife.

Reliability: The split-half reliability, correlating odd-even items, applying the Spearman-Brown formula for doubling the test length, was found to be $.49(\mathrm{~N}=60)$ with an index of reliability of .70. The test-retest reliability was also studied. It was found to be $.71(\mathrm{~N}=60)$ with an index of reliability of .84 . The retest was given with a time interval of 3 weeks. The r-values, .49 and .71 respectively, were found to be significant at .01 levels, showing that the questionnaire was reliable both in terms of its internal consistency and stability of scores.

Validity: The face validity of the questionnaire appeared to be fairly high as the items were prepared following intensive interviews of 100 married couples regarding their concept of happy married life. The content validity was adequately assured as only those items were selected for the initial questionnaire for which there was 100 percent agreement among the judges. The 
questionnaire was also validated against Singh's Marital Adjustment Inventory (singh, 1972). The coefficient correlation between the questionnaire and Singh's Marital Adjustment Inventory for a group of 20 wives was found to be .71 with index of reliability of .84 .

\section{RESULTS AND DISCUSSION}

Table 3.1: Showing means difference of marital adjustment among women of nuclear and joint families.

\section{Independent Samples Test}

\begin{tabular}{|c|c|c|c|c|c|c|}
\hline Type of Family & $\mathbf{N}$ & Mean & SD & $t$ & $d f$ & $\begin{array}{l}\text { Sig. (2- } \\
\text { tailed) }\end{array}$ \\
\hline $\begin{array}{l}\text { Marital Adjustment Nuclear } \\
\text { Joint }\end{array}$ & $\begin{array}{l}60 \\
60\end{array}$ & $\begin{array}{l}19.45 \\
15.36\end{array}$ & $\begin{array}{l}3.629 \\
3.364\end{array}$ & 6.418 & 118 & $.000 * *$ \\
\hline
\end{tabular}

** Significant at 0.01 level of significance.

The table of group statistics presents the total no. of respondents falling in each group (nuclear=60 \& joint=60). The mean of respondents belonging to nuclear families were found 19.45 and the mean of respondents from joint families were 15.36. The difference between the means of these two groups is 4.1 ; the difference between the $S D$ of two groups is .035 . The difference of means is fair.

While analysing the means of two independent sample t-tests, results depicted that there is a statistically significant difference between the means of two groups (nuclear \& joint family type) $(t=6.418, d f=118, p<0.01)$.

Hence, it can be concluded that we can reject our $\mathrm{H}_{\mathrm{O}} 1$ "there is no significant difference in marital adjustment among women with reference to their type of family (nuclear and joint families)" and say that there is a significant difference of marital adjustment in nuclear and joint families.

\section{DISCUSSION}

One of the most important relationships between a man and woman is marriage. It involves emotional and legal commitment that is very crucial in any adult life. People marry for many reasons like love, happiness, companionship, desire to start their own family and physical attraction. Positive marital adjustment means a woman is not sacrificing her own comfort zone due to the demand made by her family and spouse. While on the other hand, if a woman is sacrificing her basic requirements as well as her comforts, then it is considered as an unhealthy adjustment in her married life. 
The purpose of the study was to study marital adjustment of non-working women with reference to their type of family (nuclear \& joint families). The hypothesis of the study was that there would be no significant difference in marital adjustment among women with reference to their type of family (nuclear and joint families) is rejected. To check this difference t-test was used. The result of the present study showed that there is a significant difference in marital adjustment among women with reference to their type of family.

It was found that the women belonging to nuclear families showed higher levels of marital adjustment when compared to women of joint families. So the hypothesis is rejected. This result is similar with other studies such as Dhruv Tanwani (1997). While on the other hand the study conducted by Sumaira Rashid (2014) produced the opposite results that women marital satisfaction is better in joint families as compared to nuclear family system. The results of these studies showed that women belonging to joint families enjoy the joint responsibility. The reason may be is that women belonging to joint families are to more difficulties of life and hardships of lives. They have bigger challenges to meet. They have to work in parallel to other women in the family. They may have more fatigue and discomfort. In such an environment they may not be in a position to receive love and time from their partner. There may be other factors also.

\section{CONCLUSION}

Family has been recognized as a basic unit of society and is a link between individual and community. The structure of the family continues to be patriarchal. The aim of the present study was to examine the marital adjustment among women with reference to their type of family. So, it can be concluded that the marital adjustment of women belonging to nuclear families is higher than those women who are living in joint families. This is a signal of increasing nuclear families that marital adjustment is possible only in individual families. But the utility of joint families can't be denied because of its nature of joint responsibility.

\section{REFERENCES}

Aminjafari, A.; Padash, Z.; Baghban, I. \& Abedi, M. R. (2012). The study of marital adjustment in employer's dual career families. Interdisciplinary Journal of Contemporary Research in Business, Vol. (3) 12, pp. 559-517.

Desai, M. (1994). Concept and conceptual frameworks for understanding family. Enhancing the role of the family as an agency for social and economic development (Unit for Family Studies Report, pp.16-41). Bombay, India: TISS.

Dhruv Tanwani (1997). Marital adjustment in tribal and non-tribal working women.

Fonseca, A. (2009). Transferencia Condicionadas, Estrategias de Combate al Hambre yla desnutrición en América Latina y el Caribe, Roma: FAO.

Goel, S.; Narang, D. K. \& Koradia, N. K. (2013). Marital adjustment and mental health among bank employees and doctors during middle age in Delhi. International Journal of Scientific and Research Publications, Vol. 3 (1), pp. 1-8. 
Hashmi HA, Khurshid M, Hassan I. (2007).Marital Adjustment, Stress and Depression among Working and Non-Working Married Women. Internet Journal of Medical Update, Vol.,2(1), pp.:19-26.

Kalpana, D. B.;Pravin, A. B., (2013). A study of marital adjustment in relation to some psychosocio factor. International Journal of Humanities and Social Science, Volume 2 Issue 6, PP. 08-10, Invention ISSN (Online): 2319 -7722, ISSN (Print): 2319 7714www.ijhssi.org.

Kerns, R. D. \& Turk, D. C. (1985). Health, Illness and Families. New York: Wiley.

Kumar, P., \& Rohtagi, K. (1984). Certain personality correlates of marital adjustment. Indian Journal of Social Work, 45, 325-330.

Kumar, P., \& Rohtagi, K. (1985). Marital adjustment: Study of some personality correlates. Indian Journal of Clinical Psychology, 12, 15-18.

Lewin, K. (1948). Resolving social conflicts; selected papers on group dynamics. Gertrude W. Lewin (ed.). New York : Harper \& Row.

Ministry of Home Affairs

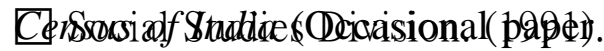
no. 1). New Delhi, India: Author.

Ramu, G. N. (1988). Wife's economic status and marriage power: A case of single- and dualearner couples. Sociological Bulletin, 37, 49-70.

Sethi B. B. (1989). Family as a potent therapeutic force. Indian Journal of Psychiatry, Vol. 31, pp. 22-30.

Shukla, A. (1988). Marital role behaviors and marital relationship among single and dual career families. Indian Journal of Clinical Psychology, 15, 84-88.

Srivastav, D., Singh, S. B., \& Nigam, J. C. (1988). Demographic characteristics and marital adjustment. Indian Journal of Clinical Psychology, 15, 89-91.

Sumaira Rashid (2014). Marital quality and family typology: Effects of Pakistani adolescent's mental health. Europeon Scientific Journal, Vol. 2, pp. 228 e ISSN: 1857-7431. 